\title{
Dental caries experience and determinants in young adults of the Northern State Medical University, Arkhangelsk, North- West Russia: a cross-sectional study
}

Sergei N. Drachev ${ }^{1,2^{*}}$, Tormod Brenn ${ }^{1}$ and Tordis A. Trovik ${ }^{1}$

\begin{abstract}
Background: Little information exists about the experience of and risk factors for dental caries in young adults in Russia. We investigated dental caries experience and determinants in medical and dental students in North-West Russia.

Methods: This cross-sectional study included 442 medical and 309 dental undergraduate students of Russian nationality aged 18-25 years from the Northern State Medical University, Arkhangelsk, Russia. Information on socio-demographic factors and oral health behaviour (regularity of dental visits, frequency of tooth-brushing, using toothpaste with fluoride, and skipping tooth-brushing) was obtained from a structured, self-administered questionnaire. Dental caries experience was based on the decayed (D) missing (M) filled (F) teeth (T) index and the Significant Caries (SiC) index, which were assessed through dental examination. Students with a DMFT index $\geq 9$ were placed in the SiC group. Negative binomial hurdle and multivariable binary logistic regressions were used for statistical analyses.

Results: The prevalence of dental caries (DMFT >0) was 96.0\%, overall mean DMFT index was 7.58 (DT: 0.61, MT: 0.12, and FT: 6.84), and the corresponding SiC index was 12.50. Age 21-25 years (incidence rate ratio [IRR] $=1.09,95 \%$ confidence interval [Cl]: 1.01-1.18), being a female (IRR $=1.10,95 \% \mathrm{Cl}$ : 1.01-1.20), high subjective socioeconomic status (SES) [IRR $=1$. 11, 95\% Cl: 1.02-1.21], and skipping tooth-brushing (IRR $=1.09,95 \% \mathrm{Cl}: 1.00-1.19)$ were associated with a higher DMFT index. DMFT index also increased among students who reported regular dental visits (IRR $=1.22,95 \% \mathrm{Cl}$ : 1.10-1.36), but their odds of being in the dental caries-free group decreased (odds ratio $[\mathrm{OR}]=0.38,95 \% \mathrm{Cl}$ : 0.18-0.82). Significant predictors of being categorised to the $\mathrm{SiC}$ group were older age (OR $=1.41,95 \% \mathrm{Cl}$ : 1.03-1.92), high subjective SES $(\mathrm{OR}=1.57,95 \% \mathrm{Cl}: 1.13-2.19)$, and regular dental visits $(\mathrm{OR}=2.34,95 \% \mathrm{Cl}: 1.56-3.51)$.
\end{abstract}

Conclusions: A high prevalence of dental caries and high DMFT index, with a dominance of FT, were observed in our Russian medical and dental students. Age, sex, subjective SES, regular dental visits, and skipping tooth-brushing were determinants of dental caries experience.

Keywords: DMFT, Young adults, Medical and dental students, North-West Russia

\footnotetext{
* Correspondence: sergei.drachev@uit.no

${ }^{1}$ Department of Community Medicine, Faculty of Health Sciences, UiT The Arctic University of Norway, N-9037 Tromsø, Norway

${ }^{2}$ International School of Public Health, Northern State Medical University,

Troickij av. 51, NSMU, ISPHA, office 1252, 163061 Arkhangelsk, Russia
} 


\section{Background}

Dental caries is a widespread chronic disease that affects billions of people worldwide. In the last decades, marked improvements in dental health have been reported in developed countries, along with an increasing proportion of dental caries-free populations, likely due to the implementation of preventive programmes such as water fluoridation, introduction of fluoride in toothpaste, and positive changes in oral health behaviour [1]. Nonetheless, global problems related to dental caries persist in most industrialised countries. The prevalence of dental caries ranges from 60 to $90 \%$ in schoolchildren and is almost $100 \%$ in adults [2]. According to the World Health Organisation (WHO), children aged 12 years are a key group that need to be monitored for dental caries. Dental caries experience at this age, expressed using the decayed (D) missing (M) filled (F) Teeth (T) index, varies from 0.2 to 7.8 across countries [3]. In Russia, the prevalence of dental caries (DMFT $>0$ ) is still high; considerably higher than in neighbouring Nordic countries. In 2009, the proportion of 12-year-olds with no dental caries experience $(\mathrm{DMFT}=0)$ was $52 \%$ in Norway and $16 \%$ in Russia [4].

Young adults aged 18-25 years are also a particularly important group in the study of dental health and its determinants. Indeed, this age range comprises periods of biological, psychological, and social development and is a transition between adolescence and adulthood, when persons take responsibility for their health and develop their own health behaviour [5]. Conscripts and students are often targeted in studies of dental health in young adults, and previous studies in these populations have been conducted in many countries, including Japan [5], Israel [6], Brazil [7], Norway [8], Australia [9, 10], Finland [11], and China [12]. Previously reported risk factors associated with dental health include socioeconomic factors (income, education, occupation) $[7,10,11]$, socio-demographic factors (age, sex, place of residence, ethnicity) [5, 10,11], oral health behaviour and attitudes $[6,12]$, and exposure to fluoridated drinking water $[10,11,13]$.

However, to our knowledge, there is little information on dental caries experience and determinants in young adults in Russia. In 2006-2008, a group of researchers conducted a study among 432 students in Moscow aged 16-25 years. They reported a high mean DMFT index (10.4) and mean DT (5.7), and the reported prevalence of dental caries was $100 \%$ and $98.3 \%$ in females and males, respectively [14]. An epidemiological survey from the Arkhangelsk Region of North-West Russia investigated the dental health of 447 conscripts aged 18-19 years and reported a prevalence of dental caries of 94.3\% and a mean DMFT of 5.9 [15]. However, both of these studies presented dental status in a descriptive manner; no determinants were studied.
Medical and dental students are expected to have specific knowledge about disease prevention and hygiene, and thereby are expected to show better oral health behaviour compared to their counterparts in the general population. In addition, students from medical and dental faculties may have high socioeconomic status (SES), which in turn may lead to better dental health [16]. Nevertheless, in 2008, an Indian study revealed that only $54.6 \%$ and $38.5 \%$ of the dental and medical students, respectively, brushed their teeth twice a day. Moreover, more than $80 \%$ of the study participants had never used dental floss [17]. In Russia, there is only one study that examined medical students, which was performed in 1987 [18]. The authors observed a high prevalence of dental caries $(98.5 \%)$ and a mean DMFT of 9.3, reflecting poor oral health.

The present study aimed to investigate dental caries experience and determinants in medical and dental students in North-West Russia.

\section{Methods}

The Northern State Medical University (NSMU) is located in Arkhangelsk, Russia. Students at the NSMU are mainly from the European North-West of Russia, which includes the regions of Arkhangelsk, Vologda, Murmansk, the Komi Republic, the Republic of Karelia, and the Nenets Autonomous Okrug. Altogether, these regions cover an area of approximately 1.5 million $\mathrm{km}^{2}$ and have a population of 4.6 million (78.9\% urban in 2016) [19].

We selected our participants from the approximately 3900 students that attended the NSMU in the 2015-2016 academic year. We invited students from two faculties to participate: 1) the medical faculty, which included students from the departments of general medicine and paediatric medicine; and 2) the dental faculty. For convenience, students from four other, smaller faculties and departments (medical prophylaxis, medical biochemistry, pharmacy, and clinical psychology) were not considered; nor were students from the international faculty of general practitioners, as we focused on students of Russian nationality only.

This cross-sectional study included two stages. At Stage 1, students from in both faculties and all years of education (6 years for medical students and 5 years for dental students) were informed about the study and invited to participate at the end of a scheduled curriculum classroom lecture. Altogether, 1579 students attended this lecture and were invited to Stage 1. The overall attendance rate of the lectures was $78.7 \%$ and varied from $55.1 \%$ (6th-year medical students) to $100 \%$ (4th-year medical students). Of the invited students, 1385 agreed to participate (overall response rate $87.7 \%$ ). During the last $15 \mathrm{~min}$ of the lecture, they signed the informed consent form and completed a structured, self-administered, 
anonymous questionnaire in Russian under the supervision of the main researcher (SND). The response rates were similar across the faculties and years of education (>83.3\%), except for 4th-year medical students (57.8\%). All students participating in Stage 1 gave their mobile phone number so they could be contacted for Stage 2 .

Stage 2 included the completion of a second, structured, self-administered, anonymous questionnaire and a clinical dental examination. In order to get comparable groups of medical and dental students and taking into account an outcome prevalence of 0.50 , a confidence interval (CI) of $95 \%$, and error margin of $5 \%$, the necessary sample size was calculated as $\sim 380$ students in each group. Assuming that medical students may not be as supportive of the oral health study as dental students, and allowing for refusals, no-shows, and exclusions, we invited 420 dental students and 823 medical students to attend Stage 2. For medical students, a stratified random proportionate sample was selected, taking into consideration the distribution of medical students across the departments (general medicine and paediatric medicine) and years of education. Sixty-two students (57 medical and 5 dental) refused to participate in Stage 2 after invitation. We excluded 135 students (128 medical and 7 dental) who did not answer their phone at two separate calls on two separate days and 145 students (125 medical and 20 dental) who did not attend the clinical dental appointment. Ninety-four students (39 medical and 55 dental) were also excluded due to the exclusion criteria for the clinical dental examination (age under 18 or over 25 years, non-Russian nationality, presence of fixed orthodontics bands, and pregnancy). The response rate was $57.6 \%$ and $79.3 \%$ in medical and dental students, respectively, and varied across years of education (41.5-69.1\% and 70.3-85.4\%, respectively). Finally, 56 students with missing data in the questionnaires were excluded. Thus the final sample for analysis consisted of 442 medical and 309 dental students (Fig. 1).

\section{Data collection}

The Stage 1 questionnaire collected information on sociodemographic variables, as well as data on oral health behaviour. Age was categorised as $18-20$ and $21-25$ years in order to get results that could be compared with those of other studies. Other socio-demographic variables included sex, faculty (medical/dental), childhood place of residence (urban/rural), and location of finishing school (Arkhangelsk City/Arkhangelsk Region/other regions). The questionnaire also asked the student to report whether they were eligible for free education (no/yes) and their type of accommodation (hostel/flat or house). A university applicant who does not qualify for free education at the NSMU can still study there, but they must pay tuition each year.
Questions on oral health behaviour included frequency of tooth-brushing (infrequent, i.e., never/less than once a week/once every few days/once a day; or frequent, i.e., twice a day/more than twice a day), using toothpaste with fluoride (without fluoride/difficult to answer; or with fluoride), and skipping tooth-brushing (no, i.e., never or almost never; and yes, i.e., sometimes during a week/every day or almost every day). Regularity of dental visits was categorised as regular (at least once every 6 months/at least once a year) and not regular (occasionally/no visits during the last 3 years). The option 'difficult to answer' was chosen only twice in response to regularity of dental visits and thus was considered as missing in the analysis.

The Stage 2 questionnaire collected additional information on socio-demographic variables. Mother's education was categorised as lower than university (high school: 9-11 years of school; specialised secondary: professional, medical, or pedagogical college, technicum) and university. The response 'difficult to answer' was considered as a missing value. Subjective SES was assessed using the MacArthur Scale [20], in which students self-reported the ranking of their family in Russian society on a ladder with 10 rungs in accordance with socioeconomic indicators (education, income, occupation): 10 was 'best off' and 1 was 'worst off'. Given the skewed distribution of SES and using the median SES (6.0) as the cut-off, those who gave a rating of $1-5$ were categorised as having low subjective SES and those responding 6-10 as having high subjective SES.

The authors developed the questionnaire in English and two independent persons translated/back-translated to Russian. The final versions were discussed and were judged to concur with the original. Before the study began, the questionnaires were tested on 12 students randomly selected from the target age group who did not participate in the study. No adjustments were necessary.

A non-invasive clinical dental examination was performed at the Dental Clinic of the NSMU from February to May 2016. The students were examined in a dental chair under a professional light, using a dental plain mirror and a dental probe without radiographs. One researcher (SND) executed all clinical examinations and dictated observations to an assistant in the room, who recorded them on a clinical form. Clinical criteria for dental caries were applied in accordance with WHO recommendations (i.e., when a lesion of the tooth's surface had an unmistakable cavity, undermined enamel, or a detectably softened floor or wall) [21]. All permanent teeth, excluding wisdom teeth, were taken into consideration during the clinical examination. The researcher was carefully calibrated on examination technics and diagnostic thresholds at the Dental Clinic of UiT The Arctic University of Norway, Tromsø, 


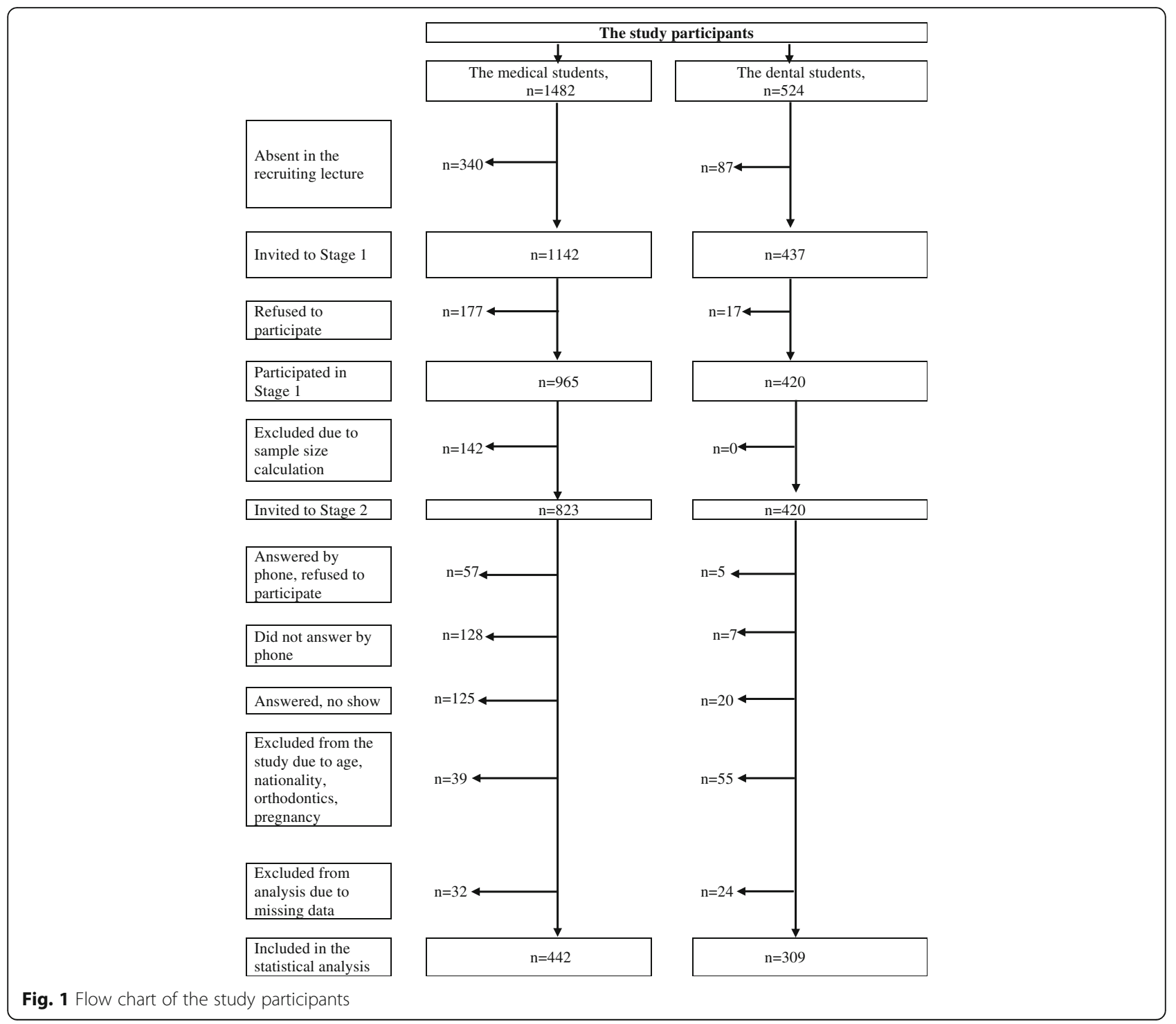

Norway, before the study start. Information from the dental clinical examination was used to calculate DMFT index. The Significant Caries $(\mathrm{SiC})$ index was computed as the mean DMFT index in the tertile of participants with the highest DMFT index [22]. The DMFT cut-off point in this subgroup was 9 , thus all students with a DMFT index $\geq 9$ were placed in the $\mathrm{SiC}$ group.

Fifty-four $(7 \%)$ of the examined students were selected randomly for clinical re-examination in June 2016. To ensure reliability, Cohen's Kappa and intraclass correlation coefficients (ICC) were calculated for dichotomous and quantitative data, respectively. The Kappa statistic for DT and non DT teeth was 0.804 (95\% CI: 0.641-0.967), signifying a strong agreement [23]. For DMFT index, the ICC was 0.989 (95\% CI: 0.981-0.993).

\section{Statistical analysis}

Data analysis was performed with IBM SPSS Statistics for Macintosh version 23.0 (IBM Corp., Armonk, New York, USA) and STATA version 14.0 (StataCorp, College Station, Texas, USA). Given the skewed distribution of the DMFT index, the Mann-Whitney $U$ and Kruskal-Wallis tests were used to compare two and more than two independent groups, respectively. For qualitative data, the chi-square test was applied.

The Poisson model, the negative binomial model, the zero-inflated (ZI) models, and the hurdle models were taken into consideration to explore the effects of sociodemographic factors and oral health behaviour on DMFT index. The significant likelihood-ratio test of alpha (chi-square $=267.2, p<0.001)$ indicated that the data were over-dispersed and that negative binomial 
regression fitted the data better than Poisson regression. Moreover, the significant Vuong test $(\mathrm{z}=3.10, p=0.001)$ showed an excessive number of zeros. For outcome distributions with over-dispersion and an excess of zeros, the zero-inflated negative binomial model or the negative binomial hurdle $(\mathrm{NBH})$ model are recommended [24]. Both ZI and hurdle models consist of a zero part and a count distribution part. In ZI models, zeros can be specified in either the zero part (structural zeros) or in the count distribution part (sampling zeros), which often leads to an incorrect or imprecise interpretation of the results [25]. In contrast, the two parts of hurdle models are clearly separated, and all zeros are modeled only in the zero part, while the count part (or zero-truncated part) deals with values over zero. For this reason, hurdle models have an easier and less misleading interpretation [24]. Therefore, we applied NBH analysis that included two separate models: a logistic regression and a zerotruncated negative binomial regression. The first model predicts whether or not a student experiences dental caries (i.e., DMFT $>0$ vs. DMFT $=0$ ). The second model was generated to predict the DMFT index for students with dental caries experience. Two sets of predictors were used for different parts of the $\mathrm{NBH}$ regression model. The selection of variables included in logistic and zero-truncated parts of the NBH model was determined by their level of significance (less than 0.2) in univariable analysis for the proportion of dental caries-free students $(\mathrm{DMFT}=0)$ and mean DMFT index (DMFT $>0$ ), respectively. To adjust for heterogeneity, Huber-White sandwich estimates for standard errors (robust estimates) were applied.

In addition to the NBH analysis, we used multivariable binary logistic regression to evaluate the odds ratios (OR) of being categorised to the $\mathrm{SiC}$ group in relation to selected socio-demographic and oral behavioural determinants. Whether a student was in the $\mathrm{SiC}$ group or not was considered as the dependent variable. All variables with a level of significance less than 0.2 in the univariable analysis were included in the multivariable regression model simultaneously. The level of significance for testing all statistical hypotheses was set at $p=0.05$.

\section{Results}

A total of 751 students were included in the statistical analysis, and the majority were women $(n=564)$. Mean age of the students was 20.2 years (standard deviation [SD] 1.6). Seventy-two percent of the participants reported an urban childhood area of residence, and more than $80 \%$ of the students came from the Arkhangelsk Region or other regions of North-West Russia. Almost $80 \%$ of the participants were eligible for free education and $64 \%$ lived in flat or house. The mothers of $45 \%$ of the participants had an education level that was lower than university. When looking at oral health behaviour, $78 \%$ of participants reported regular dental visits, $47 \%$ reported using a toothpaste with fluoride, and $81 \%$ reported frequent tooth-brushing. However, $34 \%$ of the students reported skipping tooth-brushing once a week, every day, or almost every day.

The prevalence of dental caries (DMFT $>0$ ) among the participants was $96.0 \%$. The overall mean DMFT index was 7.58 (SD 4.4); DT: 0.61 (SD 1.2), MT: 0.12 (SD 0.4), and FT: 6.84 (SD 4.1), with FT accounting for $90.2 \%$ of dental caries experience. FT constituted the main fraction of the DMFT index, both in medical $(89.8 \%)$ and dental (91.0\%) students. The $\mathrm{SiC}$ index was 12.50 (SD 3.0); DT: 0.99 (SD 1.5), MT: 0.26 (SD 0.6), and FT: 11.25 (SD 2.9), with FT accounting for 90.0\%. There were 283 students (37.7\%) in the SiC group (DMFT $\geq 9$ ) (Fig. 2).

There were no statistically significant differences in the prevalence of dental caries across the sociodemographic characteristics considered. The mean DMFT in students with dental caries experience and the proportion of students in the $\mathrm{SiC}$ group (DMFT $\geq 9$ ) were significantly higher among participants aged 21-25 years than among their younger counterparts (8.3 vs. 7.6 and $43 \%$ vs. $34 \%$, respectively). Students with dental caries experience who were not eligible for free education had a lower DMFT index compared to those who were eligible for free education. Students with higher subjective SES had a significantly higher DMFT index (8.2 vs. 7.4) and presented in the $\mathrm{SiC}$ group more frequently ( $41 \%$ vs. $31 \%)$. No statistically significant differences in the mean DMFT index and proportion of students in the $\mathrm{SiC}$ group were observed across age, sex, faculty, place of childhood residence, location of

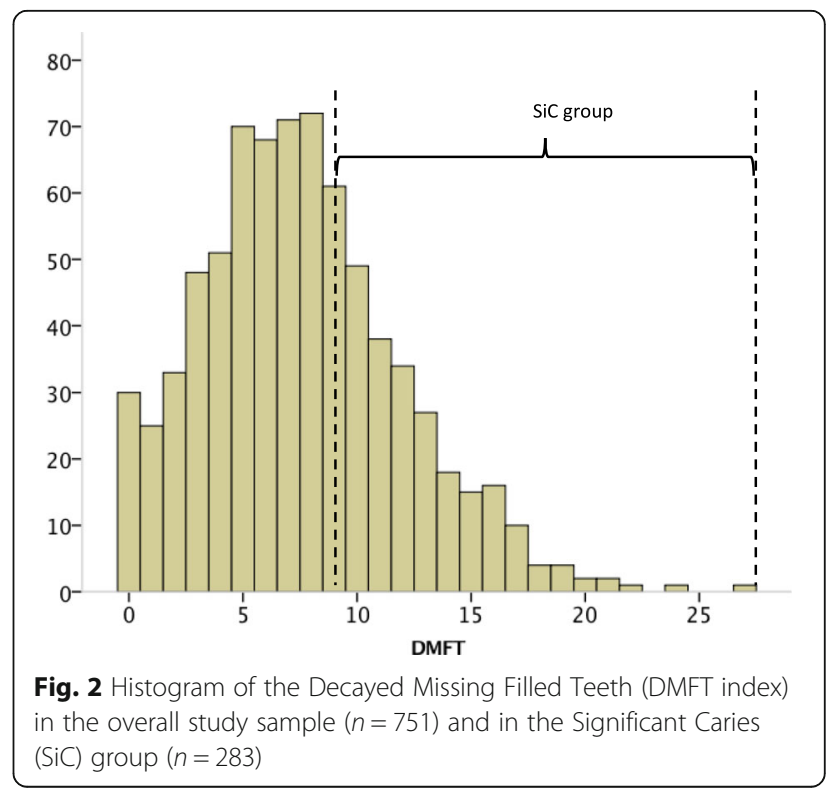


finishing school, accommodation, and level of mother's education (Table 1).

Students who reported regular dental visits had a higher prevalence of dental caries and a higher DMFT index, fewer DT (0.56 vs. 0.81, $p=0.025)$, more FT (7.28 vs. 5.33, $\mathrm{p}<0.001)$, and were more frequently in the $\mathrm{SiC}$ group compared to those who did not report such visits. No statistically significant differences were found in the prevalence of dental caries or the DMFT index among categories of tooth-brushing, skipping tooth-brushing, or toothpaste (Table 2).

The results of NBH are shown separately for the logistic and zero-truncated negative binomial parts (Table 3 ). Regular dental visits were significantly associated with lower odds of being in the dental caries-free group (OR
$=0.38,95 \%$ CI: 0.18-0.82). Furthermore, students who reported regular dental visits had an adjusted DMFT index that was 1.22 (95\% CI: 1.10-1.36) times higher than that observed in those who did not report such visits. The DMFT index of students aged 21-25 years was 1.09 (95\% CI: 1.01-1.18) times higher than that predicted in their younger counterparts, after adjustment for other variables in the model. Being a female, skipping tooth-brushing, and high subjective SES were also found to be significant independent determinants of high DMFT index.

Significant predictors of being categorised to the $\mathrm{SiC}$ group were older age $(\mathrm{OR}=1.41,95 \% \mathrm{CI}$ : 1.03-1.92), high subjective SES (OR $=1.57$, 95\% CI: 1.13-2.19), and regular dental visits $(\mathrm{OR}=2.34,95 \% \mathrm{CI}: 1.56-3.51)$ (Table 4).

Table 1 Socio-demographic characteristics associated with dental caries experience in the study sample

\begin{tabular}{|c|c|c|c|c|c|c|c|}
\hline & All $n$ & $\mathrm{DMFT}=0(\%)$ & $p^{*}$ & DMFT >0, mean (SD) & $p^{* *}$ & $\mathrm{SiC}$ gr n (\%) & $p^{*}$ \\
\hline Age group (years) & & & 0.054 & & 0.028 & & 0.020 \\
\hline $18-20$ & 449 & (5.1) & & $7.62(4.10)$ & & $154(34.3)$ & \\
\hline $21-25$ & 302 & $(2.3)$ & & $8.30(4.33)$ & & $129(42.7)$ & \\
\hline Sex & & & 0.657 & & 0.053 & & 0.068 \\
\hline Male & 187 & $(4.8)$ & & $7.31(3.79)$ & & $60(32.1)$ & \\
\hline Female & 564 & (3.7) & & $8.09(4.32)$ & & $223(39.5)$ & \\
\hline Faculty & & & 0.611 & & 0.062 & & 0.149 \\
\hline Medical & 442 & $(4.3)$ & & $8.12(4.26)$ & & $176(39.8)$ & \\
\hline Dental & 309 & (3.6) & & $7.58(4.13)$ & & 107 (34.6) & \\
\hline Place of childhood residence & & & 0.398 & & 0.725 & & 0.821 \\
\hline Urban & 537 & $(4.5)$ & & $7.91(4.18)$ & & $201(37.4)$ & \\
\hline Rural & 214 & (2.8) & & $7.86(4.30)$ & & $82(38.3)$ & \\
\hline Location of finishing school & & & 0.547 & & 0.951 & & 0.485 \\
\hline Arkhangelsk City & 146 & (5.5) & & $7.92(4.56)$ & & 49 (33.6) & \\
\hline Arkhangelsk Region & 302 & (3.3) & & $7.84(4.09)$ & & $119(39.4)$ & \\
\hline Other regions of North-West Russia ${ }^{a}$ & 303 & $(4.0)$ & & $7.94(4.17)$ & & $115(38.0)$ & \\
\hline Eligible for free education & & & 0.408 & & 0.016 & & 0.164 \\
\hline Yes & 593 & $(4.4)$ & & $8.07(4.17)$ & & $231(39.0)$ & \\
\hline No & 158 & $(2.5)$ & & $7.26(4.29)$ & & $52(32.9)$ & \\
\hline Subjective SES & & & 0.598 & & 0.013 & & 0.005 \\
\hline Less than 6.0 & 259 & (3.5) & & $7.36(3.97)$ & & $80(30.9)$ & \\
\hline 6.0 and more & 492 & $(4.3)$ & & $8.18(4.31)$ & & $203(41.3)$ & \\
\hline Accommodation & & & 0.149 & & 0.454 & & 0.345 \\
\hline Hostel & 268 & $(2.6)$ & & $7.80(4.15)$ & & $107(39.9)$ & \\
\hline Flat/house & 483 & (4.8) & & $8.05(4.31)$ & & $176(36.4)$ & \\
\hline Mother's education & & & 0.084 & & 0.095 & & 0.199 \\
\hline Lower than university & 341 & (2.6) & & $7.70(4.42)$ & & $120(35.2)$ & \\
\hline University & 410 & (5.1) & & $8.06(4.02)$ & & 163 (39.8) & \\
\hline
\end{tabular}

Abbreviations: DMFT Decayed Missing and Filled Permanent Teeth, SD Standard Deviation, SiC gr Significant Caries group, SES socioeconomic status ${ }^{a}$ Vologda Region, Komi Republic, Murmansk Region, Republic of Karelia or Nenets Autonomous Okrug

* $p$-value from the Chi square test; ${ }^{* *} p$-value from the Mann-Whitney $U$ test for two independent groups and the Kruskal-Wallis test for three independent groups 
Table 2 Oral health behaviours associated with dental caries experience in the study sample

\begin{tabular}{|c|c|c|c|c|c|c|c|}
\hline & All $n$ & $\mathrm{DMFT}=0$ (\%) & $p^{*}$ & DMFT >0, mean (SD) & $p^{* *}$ & $\mathrm{SiC}$ gr n (\%) & $p^{*}$ \\
\hline $\begin{array}{l}\text { Regularity of } \\
\text { dental visits }\end{array}$ & & & 0.030 & & $<0.001$ & & $<0.001$ \\
\hline Regularly & 584 & (3.1) & & $8.21(4.18)$ & & $244(41.8)$ & \\
\hline Not regularly & 167 & $(7.2)$ & & $6.75(4.13)$ & & 39 (23.4) & \\
\hline Tooth-brushing & & & 0.723 & & 0.904 & & 0.532 \\
\hline Infrequent & 144 & (4.9) & & $7.74(4.09)$ & & $51(35.4)$ & \\
\hline Frequent & 607 & (3.8) & & $7.93(4.24)$ & & $232(38.2)$ & \\
\hline Toothpaste & & & 0.122 & & 0.159 & & 0.334 \\
\hline $\begin{array}{l}\text { Without } \\
\text { fluoride or } \\
\text { difficult to } \\
\text { answer }\end{array}$ & 397 & $(5.0)$ & & $8.12(4.27)$ & & $156(39.3)$ & \\
\hline With fluoride & 354 & $(2.8)$ & & $7.64(4.13)$ & & $127(35.9)$ & \\
\hline $\begin{array}{l}\text { Skipping } \\
\text { tooth-brushing }\end{array}$ & & & 0.100 & & 0.179 & & 0.347 \\
\hline No & 496 & (4.8) & & 7.74 (4.19) & & $181(36.5)$ & \\
\hline Yes & 255 & (2.4) & & $8.18(4.23)$ & & $102(40.0)$ & \\
\hline
\end{tabular}

Abbreviations: DMFT Decayed Missing and Filled Permanent Teeth, SD Standard Deviation, SiC gr Significant Caries group

${ }^{*}$ p-value from the Chi square test; ${ }^{* *} \mathrm{p}$-value from the Mann-Whitney $U$ test for two independent groups

\section{Discussion}

Our study showed high dental caries prevalence and high dental caries experience with dominance of FT among undergraduate medical and dental Russian students aged 18-25 years in North-West Russia. Age, sex, subjective SES, skipping tooth-brushing, and regular dental visits were found to be significant determinants of DMFT index.

This is the first study in North-West Russia in almost 20 years to investigate dental caries experience and its determinants in young adults aged 18-25 years. The dental health status reported in this study was based on clinical dental examination and reliability tests showed the consistency of the obtained data. The overall response rate was quite high: $87.7 \%$ and $64.9 \%$ for Stages 1 and 2 , respectively.

However, this study does have some limitations. Firstly, due to its cross-sectional design, this study does not allow us to evaluate causal relationships, risk of dental caries development, or trends in the prevalence of dental caries and dental caries experience over time. Secondly, we included only medical and dental students from the NSMU; therefore the generalisability of the results to other young adults may be questioned. We assume that medical and dental students are, to some extent, a prosperous group of young people with regard to SES and health-related issues, including dental health. However, the participants reported a subjective SES of regular/good (median of MacArthur scale is 6.0), indicating that they perceived themselves to belong to a group not far from the average. On the other hand, information on SES and oral health behaviour in the present study was self-reported; thus the possibility of bias due to under- or over-reporting cannot be excluded. Thirdly, only visual and tactile methods were applied for dental caries detection; radiographs were not taken, which could lead to an underestimation of dental caries.

The prevalence of dental caries among medical and dental students in the present study (95.7\% and 96.4\%) was higher than that reported in Spain $(82.2 \%$ and $83.0 \%$ at the start and $91.1 \%$ and $87.2 \%$ at the end of study) [26] and in Yemen (81.7\% and 85.0\%) [16]. A similar pattern was observed in relation to the extent of dental caries experience, as measured by the high mean DMFT index of 7.6, which shows that the dental health of medical and dental students in North-West Russia is worse than that reported in Spain [26], India [17], and Yemen [16]. We did not find differences in the DMFT index of medical and dental students, which is in contrast with other studies. In 2002, Spanish researchers performed a longitudinal study and reported that medical students had a lower DMFT index than dental students: $3.4 \mathrm{vs.}$ 5.0 in the third year, and 4.3 vs. 5.9 in the fifth year of education [26]. In contrast, an Indian study found a mean DMFT index of 1.2 in dental students vs. 2.0 in medical students [17]. Nevertheless, in 2008-2009, Halboub et al. examined a sample of students from the faculties of medicine, dentistry, and literature at Sana'a University, Yemen, and also found no statistically significant differences in overall DMFT index between the faculties (3.9, 4.3, and 4.2, respectively) [16]. Our finding may be explained by the fact that dental caries is a slow 
Table 3 Association between the DMFT index and selected determinants in the negative binomial hurdle model

\begin{tabular}{|c|c|c|c|c|}
\hline \multirow[t]{2}{*}{ Determinants $^{\mathrm{a}}$} & \multicolumn{2}{|c|}{ Logistic regression $^{\mathrm{b}}$} & \multicolumn{2}{|c|}{$\begin{array}{l}\text { Zero-truncated negative } \\
\text { binomial regression }{ }^{c}\end{array}$} \\
\hline & OR $(95 \% \mathrm{Cl})$ & $p$-value & IRR (95\%Cl) & $p$-value \\
\hline Age group (years) & & 0.164 & & 0.031 \\
\hline $21-25$ & $0.52(0.21-1.30)$ & & $1.09(1.01-1.18)$ & \\
\hline $18-20$ & Reference & & Reference & \\
\hline Sex & & & & 0.037 \\
\hline Female & & & $1.10(1.01-1.20)$ & \\
\hline Male & & & Reference & \\
\hline Faculty & & & & 0.283 \\
\hline Dental & & & $0.95(0.88-1.04)$ & \\
\hline Medical & & & Reference & \\
\hline $\begin{array}{l}\text { Eligible for } \\
\text { free education }\end{array}$ & & & & 0.172 \\
\hline No & & & $0.93(0.83-1.03)$ & \\
\hline Yes & & & Reference & \\
\hline Subjective SES & & & & 0.015 \\
\hline 6.0 and more & & & $1.11(1.02-1.21)$ & \\
\hline Less than 6.0 & & & Reference & \\
\hline Accommodation & & 0.361 & & \\
\hline Hostel & $0.65(0.25-1.64)$ & & & \\
\hline Flat or house & Reference & & & \\
\hline Mother's education & & 0.093 & & 0.287 \\
\hline University & $1.99(0.89-4.42)$ & & $1.04(0.96-1.13)$ & \\
\hline $\begin{array}{l}\text { Lower than } \\
\text { university }\end{array}$ & Reference & & Reference & \\
\hline $\begin{array}{l}\text { Skipping } \\
\text { tooth-brushing }\end{array}$ & & 0.061 & & 0.047 \\
\hline Yes & $0.41(0.16-1.04)$ & & $1.09(1.00-1.19)$ & \\
\hline No & Reference & & Reference & \\
\hline Toothpaste & & 0.143 & & 0.117 \\
\hline With fluoride & $0.56(0.26-1.22)$ & & $0.94(0.87-1.02)$ & \\
\hline $\begin{array}{l}\text { Without fluoride } \\
\text { or difficult to } \\
\text { answer }\end{array}$ & Reference & & Reference & \\
\hline $\begin{array}{l}\text { Regularity of } \\
\text { dental visits }\end{array}$ & & 0.013 & & $<0.001$ \\
\hline Regularly & $0.38(0.18-0.82)$ & & $1.22(1.10-1.36)$ & \\
\hline Not regularly & Reference & & Reference & \\
\hline
\end{tabular}

Abbreviations: DMFT Decayed Missing and Filled Permanent Teeth, IRR incidence rate ratio, $\mathrm{Cl}$ confidence interval, $\mathrm{OR}$ odds ratio, SES socioeconomic status

accommodation was included only in the logistic regression. Sex, Faculty, Eligible for free education, and Subjective SES were included only in the zerotruncated negative binominal regression

${ }^{\mathrm{b}}$ The dependent variable was whether a student was dental caries-free (coded as 1) or not (coded as 0 )

${ }^{{ }^{\top}}$ The dependent variable was the count zero-truncated variable (DMFT >0)
Table 4 Adjusted odds ratio of being in the Significant Caries group for selected determinants

\begin{tabular}{|c|c|c|}
\hline Determinants $^{\mathrm{a}}$ & Adjusted OR (95\% Cl) & $p$-value \\
\hline Age group (years) & & 0.030 \\
\hline $18-20$ & Reference & \\
\hline $21-25$ & $1.41(1.03-1.92)$ & \\
\hline Sex & & 0.271 \\
\hline Male & Reference & \\
\hline Female & $1.23(0.85-1.77)$ & \\
\hline Faculty & & 0.120 \\
\hline Medical & Reference & \\
\hline Dental & $0.77(0.56-1.07)$ & \\
\hline Subjective SES & & 0.008 \\
\hline Less than 6.0 & Reference & \\
\hline 6.0 and more & $1.57(1.13-2.19)$ & \\
\hline Eligible for free education & & 0.412 \\
\hline Yes & Reference & \\
\hline No & $0.85(0.57-1.26)$ & \\
\hline Mother's education & & 0.308 \\
\hline Lower than university & Reference & \\
\hline University & $1.18(0.86-1.61)$ & \\
\hline Regularity of dental visits & & $<0.001$ \\
\hline Not regularly & Reference & \\
\hline Regularly & $2.34(1.56-3.51)$ & \\
\hline
\end{tabular}

Abbreviations: DMFT Decayed Missing and Filled Permanent Teeth, $\mathrm{Cl}$ confidence interval, $O R$ odds ratio, SES socioeconomic status

${ }^{a}$ Results from the multivariable binary logistic regression; all listed variables were included in the model simultaneously; $\mathrm{p}$-value of the Hosmer-Lemeshow goodness of fit test $=0.474$; Negelkerke R square $=6.9 \%$

disease and its development may start long before persons decide on dental or medical education.

Other Russian studies among Perm medical students aged 19-20 years and students from Moscow aged 21-25 years found that only $1.5 \%$ [18] and $0.7 \%$ [14] were dental caries-free, respectively. In these Russian studies, published in 1987 [18] and 2009 [14], the DMFT index was even higher than ours: 9.3 and 10.4, respectively. Direct comparison of these results with our data must be done with caution due to differences in population characteristics, recruitment of the participants, and the area covered. Nonetheless, one may speculate that dental health in young adults in Russia has not significantly improved despite positive socio-economic changes in Russia over the past 30 years.

In the current study, FT constituted the main fraction of the DMFT index, both in medical (89.8\%) and dental (91.0\%) students. This fraction was very high compared to medical and dental students from India $(21.4 \%$ and 34.5\%) [17] and Yemen (54.6\% and 49.9\%) [16]. A Spanish study reported that FT accounted for $60.4 \%$ and $56.4 \%$ of dental caries experience in 3rd- and 5th-year 
medical students, respectively. In contrast, the FT fraction in dental students constituted $81.5 \%$ of the DMFT index at the start of the study and $88.5 \%$ and at the end of the study, reflecting that dental students received more dental treatment than their medical peers [26]. Other Russian studies revealed that FT scores constituted only $42.0 \%$ and $60.7 \%$ of the DMFT index in students studying in Moscow [14] and in medical students in Perm [18], respectively. High availability of dental treatment and willingness of our medical and dental students to seek such care is one possible explanation for the high fraction of FT in the DMFT index in our study sample. Indeed, in the current study $77.8 \%$ of the students reported regular dental visits.

In agreement with the world trend, the DMFT index in the present study increased significantly with age, as dental caries is an irreversible, accumulative disease. According to previous international findings, women tend to have a higher DMFT index than men [5, 27, 28]. In our study, we also found sex differences in the DMFT index in multivariable analysis. Researchers explain this fact through a complex aetiology, including hormonal fluctuations, genetic variations, different saliva composition and flow rate, dietary habits, and social roles in the family $[29,30]$.

Oral health inequalities associated with SES are widely observed, as persons with low SES have a higher risk of poor dental health in terms of dental caries [31]. We found the opposite association both in the univariable and multivariable analyses, as those with higher subjective SES had a higher DMFT index and were more likely to be in the $\mathrm{SiC}$ group. One possible explanation for our findings may be that students with higher SES tend to adapt more to a Westernised lifestyle, with frequent consumption of foods and beverages containing added sugar. Moreover, these students may seek dental treatment more often, as they have less concerns about cost. Nevertheless, as we used self-reported measures of SES, our results might be biased compared to other studies that used education, occupation, or income as more objective indicators of SES.

The importance of oral health behaviour in maintaining good oral and dental health is well established. In our study, $80.8 \%$ of the medical and dental students reported brushing their teeth twice a day or more. This is higher than the percentage reported for the past 5-10 years in university students from 26 countries across Asia, Africa, and the Americas (67.2\%) [32], Turkish dental students (49.7\%) [33], Yemen students (38.1\%) [16], and Indian medical students (24.4\%) [34]. Nevertheless, the dental health of our study participants was worse than that reported in the aforementioned studies. Over-reporting of good dental behaviour by the participants, given their educational background, cannot be excluded. The fact that $34 \%$ of the students reported skipping tooth-brushing and the lack of significant differences in mean DMFT index by tooth-brushing frequency support this assumption, as do the results of the multivariable analysis: skipping tooth-brushing was a significant determinant of higher DMFT index.

Our finding that those who visit a dentist regularly have a higher DMFT is in agreement with previous Chinese [12] and Australian [35] studies. The fact that more than $90 \%$ of DMFT in our study were FT may suggest that dental services in Russia are focused on treatment, not on dental caries prevention.

The $\mathrm{SiC}$ index was introduced to focus on persons with the highest DMFT index and to solve the problem of a skewed dental caries distribution [22]. We did not find any publications on $\mathrm{SiC}$ index among medical and dental students in Russia or other countries that can be compared with our results. Nevertheless, the $\mathrm{SiC}$ index of 12.5 (with FT accounting for 90.0\%) in our study reflects a high number of students with a high DMFT index (with high FT component). The variables associated with the odds of being categorised to the $\mathrm{SiC}$ group (dental visits, subjective SES, age) were the same as those associated with high DMFT index. One may speculate that students have a lack of knowledge regarding a healthy diet and/or appropriate oral hygiene habits, which in turn may lead to frequent dental visits for dental treatment. Further studies that include information on the threshold for dental caries treatment among Russian dentists are warranted to better understand the high DMFT in our study population.

\section{Conclusions}

High dental caries prevalence and high DMFT index, with a dominance of FT, were observed among undergraduate medical and dental Russian students aged 18-25 years in North-West Russia. Age, sex, subjective SES, regular dental visits, and skipping tooth-brushing were found to be significant determinants of dental caries experience.

\section{Abbreviations \\ Cl: Confidence interval; DMFT: Decayed missing filled teeth; DT: Decayed teeth; FT: Filled teeth; ICC: Intraclass correlation coefficient; IRR: Incidence rate ratio; MT: Missing teeth; NBH: Negative binomial hurdle model; NSMU: Northern State Medical University; OR: Odds ratio; SD: Standard deviation; SES: Socioeconomic status; SiC index: Significant caries index; WHO: World health Organisation; Zl: Zero-inflated model}

\section{Acknowledgements}

We would like to thank UiT The Arctic University of Norway for financial support; the administration of NSMU for help in organisation of the data collection; all students who participated in the study; and Vitalina Yureva, Valentina Lisaya, Elena Latuhina, and Valentina Chernysheva for assistance during the field work and dataset development. 


\section{Funding}

The study was supported by a grant from the ARKTROPP, Department of Community Medicine, UiT The Arctic University of Norway. The publication charges for this article have been funded by a grant from the publication fund of UiT The Arctic University of Norway. The funding body did not play any role in the design of the study; the collection, analysis, and interpretation of data; or in the writing of the manuscript.

\section{Availability of data and materials}

The dataset used and analysed during the current study is available from the corresponding author on reasonable request.

\section{Authors' contributions}

SND and TAT created the study concept, design and methodology. SND carried out data collection and data entry. TB and TAT supervised data collection and data entry. SND, TB, and TAT analysed and interpreted the data. SND, TB, and TAT drafted, critically reviewed, commented on and revised the manuscript. All authors read and approved the final manuscript.

\section{Ethics approval and consent to participate}

The study was approved by the Regional Ethical Committee of Norway (2015/ 1788/REK nord) and the Ethical Committee of the NSMU, Russia (№ 05/10-15 from 19.10.2015). Verbal and written informed consent was obtained from every participant at Stage 1. For those willing and interested to participate in the study, the main researcher also gave assurance of confidentiality of the obtained information and stressed that the participant could withdraw from the study at any time.

\section{Consent for publication}

Not applicable.

\section{Competing interests}

The authors declare that they have no competing interests.

\section{Publisher's Note}

Springer Nature remains neutral with regard to jurisdictional claims in published maps and institutional affiliations.

Received: 27 April 2017 Accepted: 19 November 2017 Published online: 28 November 2017

\section{References}

1. Lagerweij MD, van Loveren C. Declining caries trends: are we satisfied? Curr Oral Health Rep. 2015;2:212-7.

2. Petersen $\mathrm{PE}$, Bourgeois D, Ogawa $\mathrm{H}$, Estupinan-Day S, Ndiaye C. The global burden of oral diseases and risks to oral health. Bull World Health Organ. 2005;83:661-9.

3. da Silveira Moreira R. Epidemiology of dental caries in the world. In: Virdi PM, editor. Oral health care - pediatric, research, epidemiology and clinical practices. Rijeka: InTech; 2012. p. 149-68.

4. Koposova N, Eriksen HM, Widstrom E, Handegard BH, Pastbin M, Koposov R. Caries prevalence and determinants among 12-year-olds in north-West Russia and northern Norway. Stomatologija. 2013;15:3-11.

5. Kojima A, Ekuni D, Mizutani S, Furuta M, Irie K, Azuma T, et al. Relationships between self-rated oral health, subjective symptoms, oral health behavior and clinical conditions in Japanese university students: a cross-sectional survey at Okayama University. BMC Oral Health. 2013;13:62.

6. Levin L, Shenkman A. The relationship between dental caries status and ora health attitudes and behavior in young Israeli adults. J Dent Educ. 2004;68: 1185-91.

7. Peres MA, Peres KG, Traebert J, Zabot NE, Lacerda JT. Prevalence and severity of dental caries are associated with the worst socioeconomic conditions: a Brazilian cross-sectional study among 18-year-old males. J Adolesc Health. 2005;37:103-9.

8. Statistics Norway. Tannhelsetenesta, 2014. https://www.ssb.no/helse/ statistikker/tannhelse/aar/2015-07-02. Accessed 10 Dec 2016.

9. Hopcraft MS, Yapp KE, Mahoney G, Morgan MV. Dental caries experience in young Australian Army recruits 2008. Aust Dent J. 2009:54:316-22.

10. Hopcraft M, Morgan MV. Dental caries experience in Australian Army recruits 2002-2003. Aust Dent J. 2005;50:16-20.
11. Kamppi A, Tanner T, Pakkila J, Patinen P, Jarvelin MR, Tjaderhane $L$, et al. Geographical distribution of dental caries prevalence and associated factors in young adults in Finland. Caries Res. 2013;47:346-54.

12. HX L, Wong MC, Lo EC, McGrath C. Risk indicators of oral health status among young adults aged 18 years analyzed by negative binomial regression. BMC Oral Health. 2013;13:40.

13. Hopcraft M, Morgan M. Dental caries experience in a young adult military population. Aust Dent J. 2003:48:125-9.

14. Makeeva IM, Doroshina V. Protsenko AS. [prevalence of dental diseases among Moscow students and need of dentistry]. Stomatologiia (Mosk). 2009:88:4-8. Russian

15. Ushmanova TN, Obraztsov UL. Oral health of population in north-west of Russia. Arkhangelsk: Northern State Medical University; 2001. Russian

16. Halboub E, Dhaifullah E, Yasin R. Determinants of dental health status and dental health behavior among Sana'a university students, Yemen.J Investig Clin Dent. 2013;4:257-64

17. Kumar S, Motwani K, Dak N, Balasubramanyam G, Duraiswamy P, Kulkarni S. Dental health behaviour in relation to caries status among medical and dental undergraduate students of Udaipur district, India. Int J Dent Hyg. 2010;8:86-94.

18. Tomenko EK, Shur LF, Sirotina TL, Pavlova GA, Balueva NM. Risk factors in the occurrence of caries in students at perm medical institute. Stomatologiia (Mosk). 1987;66:30-1. Russian

19. Rosstat. Population and area of Russia by regions. http://www.statdata.ru/. Accessed 12 Oct 2016

20. Adler NE, Epel ES, Castellazzo G, Ickovics JR. Relationship of subjective and objective social status with psychological and physiological functioning: preliminary data in healthy white women. Health Psychol. 2000;19:586-92.

21. World Health Organization. Oral health surveys: basic methods - 5th edition. Geneva: World Health Organization; 2013.

22. Significant Caries Index. https://www.mah.se/CAPP/Methods-and-Indices/forCaries-prevalence/Significant-Caries-Index/. Accessed 12 Nov 2016.

23. McHugh ML. Interrater reliability: the kappa statistic. Biochem Med (Zagreb). 2012;22:276-82

24. Hofstetter H, Dusseldorp E, Zeileis A, Schuller AA. Modeling caries experience: advantages of the use of the hurdle model. Caries Res. 2016; 50(6):517-26.

25. Preisser JS, Stamm JW, Long DL, Kincade ME. Review and recommendations for zero-inflated count regression modeling of dental caries indices in epidemiological studies. Caries Res. 2012;46:413-23.

26. Cortes FJ, Nevot C, Ramon JM, Cuenca E. The evolution of dental health in dental students at the University of Barcelona. J Dent Educ. 2002;66:1203-8.

27. Zemaitiene M, Grigalauskiene R, Vasiliauskiene I, Saldunaite K, Razmiene J, Slabsinskiene E. Prevalence and severity of dental caries among 18-year-old Lithuanian adolescents. Medicina (Kaunas). 2016;52:54-60.

28. Garcia-Cortes JO, Medina-Solis CE, Loyola-Rodriguez JP, Mejia-Cruz JA Medina-Cerda E, Patino-Marin N, et al. Dental caries' experience, prevalence and severity in Mexican adolescents and young adults. Rev Salud Publica (Bogota). 2009;11:82-91.

29. Lukacs JR. Sex differences in dental caries experience: clinical evidence, complex etiology. Clin Oral Investig. 2011;15:649-56.

30. Lukacs JR, Largaespada LL. Explaining sex differences in dental caries prevalence: saliva, hormones, and "life-history" etiologies. Am J Hum Biol. 2006;18:540-55

31. Schwendicke F, Dorfer CE, Schlattmann P, Foster Page L, Thomson WM, Paris S. Socioeconomic inequality and caries: a systematic review and metaanalysis. J Dent Res. 2015:94:10-8.

32. Peltzer K, Pengpid S. Oral health behaviour and social and health factors in university students from 26 low, middle and high income countries. Int J Environ Res Public Health. 2014;11:12247-60.

33. Akarslan ZZ, Sadik B, Sadik E, Erten H. Dietary habits and oral health related behaviors in relation to DMFT indexes of a group of young adult patients attending a dental school. Med Oral Patol Oral Cir Bucal. 2008;13:E800-7.

34. Kumar S, Gupta A, Dixit A, Solanki K, Balasubramanyam G, Duraiswamy P, Kulkarni S. Factors that effect dental caries status of medical students in Udaipur city, India. Int J Dent Hyg. 2010;8:110-5.

35. Roberts-Thomson K, Stewart JF. Risk indicators of caries experience among young adults. Aust Dent J. 2008:53:122-7. quiz 186 